OPEN ACCESS

Edited by:

Eirik Søvik,

Volda University College, Norway

Reviewed by:

Patrick Schultheiss,

The University of Hong Kong,

Hong Kong

Daniel Ari Friedman

Stanford University, United States

Reuven Dukas,

McMaster University, Canada

*Correspondence:

Zhanna Reznikova

zhanna@reznikova.net

Specialty section:

This article was submitted to Behavioral and Evolutionary Ecology,

a section of the journal

Frontiers in Ecology and Evolution

Received: 01 February 2021

Accepted: 15 April 2021

Published: 24 May 2021

Citation:

Reznikova Z (2021) Ants Personality and Its Dependence on

Foraging Styles: Research

Perspectives.

Front. Ecol. Evol. 9:661066. doi: 10.3389/fevo.2021.661066

\section{Ants' Personality and Its Dependence on Foraging Styles: Research Perspectives}

\author{
Zhanna Reznikova ${ }^{1,2 *}$ \\ ${ }^{1}$ Institute of Systematics and Ecology of Animals, Siberian Branch RAS, Novosibirsk, Russia, ${ }^{2} \mathrm{~V}$. Zelman Institute for \\ Medicine and Psychology, Novosibirsk State University, Novosibirsk, Russia
}

The paper is devoted to analyzing consistent individual differences in behavior, also known as "personalities," in the context of a vital ant task-the detection and transportation of food. I am trying to elucidate the extent to which collective cognition is individual-based and whether a single individual's actions can suffice to direct the entire colony or colony units. The review analyzes personalities in various insects with different life cycles and provides new insights into the role of individuals in directing group actions in ants. Although it is widely accepted that, in eusocial insects, colony personality emerges from the workers' personalities, there are only a few examples of investigations of personality at the individual level. The central question of the review is how the distribution of behavioral types and cognitive responsibilities within ant colonies depends on a species' foraging style. In the context of how workers' behavioral traits display during foraging, a crucial question is what makes an ant a scout that discovers a new food source and mobilizes its nestmates. In mass recruiting, tandem-running, and even in group-recruiting species displaying leadership, the division of labor between scouts and recruits appears to be ephemeral. There is only little, if any, evidence of ants' careers and behavioral consistency as leaders. Personal traits characterize groups of individuals at the colony level but not performers of functional roles during foraging. The leader-scouting seems to be the only known system that is based on a consistent personal difference between scouting and foraging individuals.

Keywords: ants, personality, cognition, scouts, foraging, communication, division of labor

\section{INTRODUCTION}

In more than 14,000 ant species (Bolton, 2020), foraging styles vary from solitary foraging to cooperative arrangements based on information transfer (reviews in Hölldobler and Wilson, 1990, 2009; Jackson and Ratnieks, 2006; Heinze, 2008; Leonhardt et al., 2016; Reznikova, 2020). It is challenging to find individuals' behavioral and cognitive traits in the context of the vital ant task-the detection and transportation of food. 
The term "animal personality" describes the behavioral phenotype that is consistent over time and across situations and differs between individuals of the same species (Budaev, 1998; Gosling, 2001; Drent et al., 2003). There are several other terms placed under the umbrella of "animal personality" such as "behavioral syndrome," "coping style," "pace-of-life syndromes;" however, each of them describes different aspects of behavioral phenotypes (Beekman and Jordan, 2017). While personality (a behavioral type; the individual type) is an individual-level characteristic, the term "behavioral syndrome" describes a characteristic of a population (Sih et al., 2004a,b; Bell, 2007). A behavioral syndrome is defined more broadly and involves behavioral consistency within, and also between individuals. Within-individual consistency is present when individuals invariably behave in similar situations (for a review, see Bergmüller, 2010).

Although the term "personality" seems to be borrowed from the human literature on the subject, and there are some parallels between personality in humans and other animals (Gosling, 2001; Sih et al., 2004b; Bell et al., 2009), animal personality researchers usually do not refer to cognitive or emotional processing when interpreting behavioral patterns. For example, in their study on octopuses, Mather and Anderson (1993) consider personality as a multidimensional combination of highly correlated behaviors. Studying animal personality includes observing the same individuals more than once and quantifying within- and among-individual (co)variances (Bell, 2017). Still, a few works are studying whether species show consistent withinspecies between-individual variation in cognitive abilities such as attention, learning, and memory (Sih and Del Giudice, 2012; Griffin et al., 2015; Nácarová et al., 2018; Wilson et al., 2019). Some recent studies consider cognitive characteristics as a part of personality. For instance, on the example of great tits, Nácarová et al. (2018) argue that "fast" and "slow explorers" differ in their cognitive ability to evaluate the confusing sparrow hawkpigeon chimeras. Reznikova et al. (2019) revealed significant individual variability in the ability of striped field mice to distinguish between different quantities of visual geometric stimuli. They found striking consistent individual variation in cognitive performance among wild rodents. Carpenter ants display consistent cognitive variability linked to individual peculiarities in exploratory activity (d'Ettorre et al., 2017); red wood ants demonstrate stable differences in their ability to form aversive learning after having negative encounters with their eternal enemy (hoverfly larvae), depending on their role in society (Iakovlev and Reznikova, 2019; see details in the next sections).

In sum, the importance of animal personality in animal research is becoming increasingly recognized. Whilst numerous studies highlight behavioral variation across a diverse range of species, the understanding of what drives this variation, and how it is maintained, is still limited (Gordon, 2019; Wilson et al., 2019). Investigations of consistent individual differences within the frame of animal personality provide an integrative approach to understanding animal behavior causes and mechanisms.

Among the many contexts in which inter-individual differences display, such as habitat use, reaction to predation threat, intraspecific aggression, and so on, the social context is essential because isolated individuals may often behave differently from those in groups (Webster and Ward, 2011). In social insects, most behavioral studies have been done at the colony level by essentially looking at the average reaction of the group as a whole. Although several seminal studies recently have considered personalities in social insects at multiple levels, from individuals to groups and whole colonies (Jandt et al., 2014; Wright et al., 2019; Kolay et al., 2020), the main difficulty here is that the individuals that make up a social insect colony are so highly cooperative and tightly connected that their societies are often regarded as a single super-organism (Hölldobler and Wilson, 1990, 2009; Feinerman and Korman, 2017). There are some controversies here emanating during the last decades from the arbitrarily defined sociobiological concepts of superorganismality and eusociality (Boomsma and Gawne, 2018), and it is necessary to define precisely the field of the present review.

In his influential paper "The ant colony as an organism" William Morton Wheeler (1911) defined an ant colony as an "organism" with a Weismannian germ-line and somatic "support tissues" in the form of workers and sometimes soldiers. Later Wheeler $(1920,1928)$ and Emerson (1939) applied the "superorganism" concept to eusociality in insects. Since Wheeler's crucial evolutionary innovation, the concept of superorganism applied to eusocial insect societies has been revised with the use of genetic approaches (Wilson and Sober, 1989; Wilson and Hölldobler, 2005; Hamilton and Fewell, 2013; Helanterä, 2016; Canciani et al., 2019). However, Boomsma and Gawne (2018) note that the colony-as-superorganism thesis has become a meme that bears little similarity with the original hypothesis. They argue that only Wheeler's original definition of superorganismality can be unambiguously linked to irreversible evolutionary transitions from contextdependent reproductive altruism (sensu Hamilton, 1964a,b) to unconditional differentiation of permanently unmated castes in social insects. It is worth noting that contemporary social insects papers routinely use the term eusocial when referring to social insects (usually ants) with morphologically distinct castes. Fertile queens and unmated workers evolved once in the common ancestor of all ant species (Qiu et al., 2018), and worker castes are physically different groups of female individuals that specialize in specific functions in the colony (Corona et al., 2016). The partitioning of morphological traits among colony members is typically generated by differential regulation of the genome during development (Friedman et al., 2020a). For example, soldier and queen castes have extreme trait specialization for defense and reproduction (reviews in Trible and Kronauer, 2017; Wills et al., 2018; Powell et al., 2020). Despite the long history of work on caste function, knowledge of how castes evolve adaptively across taxa is still incomplete, and the core of evolutionary mechanisms of caste development across ants remain so far obscure (Qiu et al., 2018; Powell et al., 2020). Importantly, as noted by Hölldobler and Wilson (1990), of the 297 genera described at the time, only 46 (15\%) had polymorphic species with distinct morphological castes, whereas in the rest of the species polyphenic colony phenotype 
expresses as a simple variation in adult size. Boomsma and Gawne (2018) emphasize a fundamental difference between species with permanent, morphologically differentiated castes and with behavioral "castes," that is, groups of individuals that differ only by behavioral traits. The present review considers the individual ant as a nestmate worker and behavioral castes in monomorphic ant species as a basis for analyzing worker personalities. Even with these restrictions, it is worth noting that the causes of behavioral differences within ant colonies are often difficult to reveal and explain. Colonies are comprised of individuals with different fathers (polyandry) or different mothers (polygyny) or sometimes both (Beekman and Jordan, 2017). For example, in the polyandrous desert ant Cataglyphis cursor, workers belonging to different patrilines differ in their propensity to perform a given task such as foraging, nest construction, waste management, or food storage (Eyer et al., 2013).

With all these complexities of social insects' colonies organization in mind, it is challenging to search for such answers as to which extent collective cognition is individual-based and whether a single individual's actions can direct the entire colony or at least colony units. This paper does not present final answers; however, it provides new insights into individuals' role in the direction of group actions in ants and charts some perspectives for studying ants' personalities in the context of foraging styles.

\section{WHAT DO WE KNOW ABOUT PERSONAL TRAITS IN INSECTS?}

Since the first studies on the behavioral syndrome in crickets (Kortet and Hedrick, 2007; Wilson et al., 2010), methodological approaches to studying consistent individual variations in insect behavior had much in common with those on vertebrates and included measuring several behavioral traits using various tests. For instance, cricket studies focused on correlations between activity, exploration, antipredatory behavior, aggression, mate attraction displays, and mate phonotaxis. In particular, Wilson et al. (2010) found across-context correlations that represent the boldness syndrome as individual risk-taking. Exploration appeared to be central to across-context mating and antipredation reactions.

It is worth noting that during the last two decades, a traditional belief that invertebrates are just "mini-robots," which stereotypically respond to stimuli and should exhibit few or no individual differences in behavior, has changed. Currently, a comparative personality approach includes numerous and highly diverse invertebrate taxa, mainly arthropods. Invertebrate species represent over 95\% of all animal species (Scheffers et al., 2012). These animals exhibit a range of aspects in their life histories, social and sexual behaviors that are extremely rare or absent in vertebrates, and can provide new opportunities for studying personality (review in Kralj-Fišer and Schuett, 2014).

Insects' complete metamorphosis is of vital interest here due to profound changes during life stages. An open question is how individual insects display correlated trait variation across their traits from life stages in one environment through their metamorphosis. For instance, in aquatic insects, typical larval behaviors are crawling, feeding, and swimming, whereas adult behaviors include flying and reproducing. Brodin (2009) showed that in the damselfly Lestes congener larval behavioral type can predict boldness and foraging success in adults. In insects with an incomplete metamorphosis such as crickets, crucial changes in hormones and morphology also occur when juveniles become adults. Hedrick and Kortet (2012) found that boldness (readiness to emerge from a safe refuge) in field crickets persists during metamorphosis in females but not in males. Males became timider with maturation, possibly caused by the risk associated with calling for mates.

Studying firebugs (Pyrrhocoris apterus) Gyuris et al. (2012) measured activity, boldness, and exploration twice in the larval stage and also twice when bugs reached the adult stage. Measuring fear responses (emerging from a refuge), reactions to novel objects, and activity parameters, the authors showed that the relative value of behavioral traits was stable across ontogeny. Nevertheless, larvae differed from adults in general in that they were bolder, explored their environment more thoroughly, and seemed to be more active before the final stage.

The great diversity of life-history features, short life cycles, and relatively simple nervous system combined with various behavioral patterns make insects useful and still underestimated models to study personality and its evolution. However, only a few empirical studies have investigated multiple behavioral dimensions in insects so far. There are several examples of studying behavioral syndromes in Coleoptera, or beetles, the largest order of insects representing close to $40 \%$ of insect species and a fourth of all animal species (for a review, see Labaude et al., 2018). Beetles have complete metamorphosis, and some species possess various morphs, which provides different contexts for studying consistent behavioral variabilities. Monceau et al. (2017) tested four behavioral traits in mealworm beetles (Tenebrio molitor). They found that in contrast to damselflies (Brodin, 2009), which are also holometabolous insects, in beetles, larval personality does not predict adult personality. Labaude et al. (2018) investigated the personality of a ground beetle, Nebria brevicollis, and revealed two clusters of behaviors: one grouping activity involving exploration and boldness characteristics, and a second one consisting of responses to a threat.

Research on insect personality in the field is still scarce. For example, translocation field experiments with nymphal field crickets Gryllus campestris revealed repeatability of flight initiation distance associated with risky behaviors (Niemelä et al., 2015).

\section{PERSONALITY AT THE COLONY LEVEL}

It is widely accepted that in eusocial insects, "colony personality" emerges from the personalities of the workers comprising them (Jandt et al., 2014; Feinerman and Korman, 2017; Wright et al., 2019). The first publications on behavioral syndromes and personalities in ants (Chapman et al., 2011) and honeybees (Wray et al., 2011) have already considered these phenomena at multiple levels. The mechanisms underlying consistent individual differences of insect colonies and links to the societies' 
success are not yet sufficiently understood and becoming an area of increasing interest. When using the term "collective behavior" referring to the collective action of a social insect colony, it is not necessarily meant that these actions are consistent over time and situations. Colony personalities can emerge from interactions among group members, ontogenetic processes, ecological conditions, and other processes (Horna-Lowell et al., 2021). How ant colonies behave across different situations depends, in turn, on the allocation of workers to various tasks.

As noted before, in this review, I concentrate on the species with behavioral castes, and not morphologically specialized groups of workers. Even within this group of species, various mechanisms determine task allocation and fidelity among workers. For example, some species exhibit age-related repertoire expansion, whereas, in others, workers of certain ages have strong tendencies to perform specific tasks (reviews in Hölldobler and Wilson, 2009; Giraldo and Traniello, 2014). In other species, task specialization among workers may be shaped by their size polymorphism, genetic background, experience, and social interactions, which is also partly influenced by age (review in Iakovlev and Reznikova, 2019). The allocation of workers to various tasks may depend on external cues, such as interactions among ants and changes in the environment (Gordon, 2016). In contrast to rock ants Temnothorax, with their weak task fidelity (Dornhaus, 2008; Charbonneau et al., 2017), in red wood ants Formica s.str., individuals belonging to different task groups possess standard sets of distinct behavioral features. Consistent differences between behavior of "aphid shepherds," "guards," and "carriers" were described as an example of the behavioral syndrome in this group of species (Reznikova, 2011; see details in the last section).

Chapman et al. (2011), on the example of Myrmica rubra, first demonstrated that ants exhibit behavioral syndromes at both the individual and the colony levels. At the individual level, personalities were related to task allocation: patrollers appeared to be bolder, more aggressive, and more active than members of the foraging-recruit and brood-carrier groups. Sociability was correlated with boldness at the colony level. Colonies containing individuals that spent more time contacting each other were also composed of individuals that responded boldly to an introduced alarm stimulus. Pamminger et al. (2014) found grouplevel personality in M. rubra: workers who prefer the withinnest position, low activity, and weak attraction to light were more prone to interact with brood. In contrast, high aggression and exploration were associated with traits favoring a position outside the nest, increased activity, and high attraction to light. Interestingly, entrance workers, foragers, and brood-tenders each possessed different cuticular hydrocarbon profiles.

Bengston and Dornhaus (2014) applied a variety of tests for studying the colony-level behavioral syndrome in Temnothorax rugatulus. In field and laboratory experiments, they measured foraging effort under different conditions and the colonies' responses to intruders. The colonies differed in their coping style: some were more risk-prone, whereas others were more riskaverse.

Many studies considered behavioral differences between colonies on different axes such as boldness, explorativeness, and even collective cognition and learning. However, intercolony differences in cognitive coping style remain so far obscure, and mainly inter-colony behavioral differences have been examined (for reviews see: Jandt et al., 2014; Wright et al., 2019; Horna-Lowell et al., 2021). Comparative studies on several Temnothorax species demonstrated that colonies composed of more aggressive individuals exhibit a more significant collective defensive response toward intruders (Modlmeier et al., 2014), forage more effectively (Lichtenstein et al., 2016), and are quicker at nest relocation (Modlmeier et al., 2014). In Aphaenogaster ants, aggressive colonies are also better foragers, more thoroughly explore their environment, and better at defensive responses toward intraspecific competitors than more meek colonies (Blight et al., 2016). Cecropia trees bearing more aggressive Azteca constructor ant colonies suffered less leaf damage than trees with meek colonies (Marting et al., 2018). An interesting example came recently from the "left- and right-handed" red wood ants colonies: Formica rufa show colony-level biases in different directions when tested for forelimb preference during a gap-crossing task (Calcraft et al., 2016; see also Frasnelli and Vallortigara, 2018). Long-term experiments showed that in red wood ants, different tasks performed within a colony require various cognitive skills. Thus, the cognitive ability could determine how efficient individuals and, in turn, their colonies are at performing particular tasks (Reznikova, 2008).

Much work remains to be done to understand how collective behaviors emerge and function at the colony level (Pinter-Wollman, 2012; Horna-Lowell et al., 2021). A distinct and intriguing direction in studying colony personalities is investigating how genomes govern the polymorphic social organization. Many ant species exhibit convergent behavioral syndromes in dependence on the number of queens reproducing in the colony (Purcell et al., 2014). Colonies with numerous queens (polygynous) produce smaller queens and workers than colonies with a single queen (monogynous). These two forms differ in crucial behavioral traits such as tolerance to conspecifics and the mode of dispersal (Keller, 1995). A study on the fire ant Solenopsis invicta identified a large, non-recombining "social chromosome" that is associated with alternative social organizations in that species (Wang et al., 2013). Purcell et al. (2014) investigated the genomic architecture underlying social organization in the Alpine silver ant, Formica selysi, which is polymorphic in queen number and exhibits a similar suite of behavioral traits associated with each form. A "social chromosome" in F. selysi appeared to share architectural characteristics with that of the fire ant, although the two show no detectable similarity in gene content. The discovery of convergence at the phenotype and the genetic architecture levels associated with alternative social forms suggest general genetic mechanisms underlying social organization transitions.

The adaptive significance of collective personalities and energy trade-offs associated with life-history strategies have not been sufficiently studied yet. Although many studies have linked collective personality with colony performance, so far only a few results have been obtained in nature (Wright et al., 2019). Modlmeier et al. (2012) investigated aggression, exploration, and brood care behavior in $T$. longispinosus focusing on 
the influence of these behaviors on the colony's productivity. Colonies with more intracolonial behavioral variation in brood care and exploration of novel objects appeared to be more productive than colonies with less variation. A recent study (Friedman et al., 2020b) demonstrated that in the red harvester ant (Pogonomyrmex barbatus), forager brain gene expression variation among colonies was associated with colony variation in regulation of foraging, a trait that is associated with colony reproductive success.

Bengston et al. (2017) have tested whether energy trade-offs associated with life-history strategy variation drive the behavioral syndrome related to risk-tolerance in T. rugatulus ants. The authors evaluated how colonies allocate energy to the number of workers ("somatic effort") and winged reproductive casts ("reproductive effort"). The behavioral type at the colony level appeared to be associated with a life history strategy: risktolerant colonies grew faster and invested more in reproduction, whereas risk-averse colonies had a lower growth rate but invested relatively more in workers. The tendency of risk-tolerant populations to allocate more energy toward reproduction and grow faster remained consistent during the 3 years of the study (Bengston, 2018).

Sustainable associations between behavioral traits and life strategies recently are considered a part of the pace-of-life syndrome (hereafter POLS). The general concept is that lifehistory characteristics and suites of physiological traits have coevolved in response to environmental conditions forming POLS (Ricklefs and Wikelski, 2002). The opportunities and challenges associated with including personality within the POLS concept have been initially proposed by Wolf et al. (2007); Careau et al. (2008), and Réale et al. (2010) and considered in many species including non-social insects. Recently, the POLS concept has been applied to bumblebees (Buechel and Schmid-Hempel, 2016), gypsy Aphaenogaster ants (Blight et al., 2016), and rock Temnothorax ants (Bengston et al., 2017). Segev et al. (2017) examined the persistence of behavioral syndromes at colony levels in $T$. longispinosus along a climatic gradient in North-Eastern United States. Behavioral syndromes clearly occurred across populations. Colonies from warmer environments appeared to display more active exploration and foraging and less aggressiveness than colonies from colder sites. Interestingly, some positive correlations between foraging, exploration, and aggression were more noticeable at the warmest sites, whereas negative associations were more common at colder sites. This study is consistent with the POLS model and provides insights into the adaptive value of behavioral syndromes along climatic gradients.

Studies of personalities at the group and colony levels include many different species (review in Horna-Lowell et al., 2021). However, most of them consider rock ants Temnothorax as a model to describe holistic reactions of ant communities to the internal and external environmental challenges (Jandt et al., 2014; Lichtenstein et al., 2016; Segev et al., 2017; Bengston, 2018, and some others cited above). This choice of species is of little help to answer the central question of the present review-the role of the individual in the colony-because rock ants, with their tiny colonies, use a relatively simple division of labor. In the subsequent sections, I consider how the distribution of behavioral traits and cognitive responsibilities within ant colonies depends on the species' foraging style.

\section{ANTS' BEHAVIORAL AND COGNITIVE TRAITS IN THE CONTEXT OF FORAGING STYLES}

In ants, foraging styles display a continuum from individual to cooperative behaviors. Recruitment is defined as the communication that attracts nestmates to some point in space where work is required (Wilson, 1971). Recruitment to a food source, which is the focus of this review, includes any behavior by which a worker summons nestmates to a place of interest. It takes a variety of forms across ant species. There are different methods of classification of modes of recruitment in ants (Lanan, 2014; Reeves and Moreau, 2019; Kolay et al., 2020). In this review, I refer to the following four main categories of recruitment strategy (Figure 1; see the detailed review in Reznikova, 2020): (1) Mass recruitment, in which scouting individuals broadcast guidance information to their nestmates in the form of a scent trail. (2) Tandem running, where a successful scout leads a single recruit to the resource found earlier. (3) Group recruitment: a scouting ant may lead a group of several individuals to a goal. (4) "Leader-scouting" system in which a scout communicates a distant location to foragers. In this system, messages about distant goals come from the scouting ant, without relying on any other cues such as odor trails or direct guidance.

Most ant species use a single foraging strategy but some species employ several, and they can also switch between various strategies depending on environmental stimuli, such as the size of the food sources, as well as internal stimuli, such as colony growth (the reviews in Reznikova, 2017, 2020). Interestingly, the choice of the foraging strategy can be determined by the first forager, which is able to modify its behavior according to the food supply volume or the food quality (Dlussky et al., 1978; de Biseau and Pasteels, 1994; Mercier and Lenoir, 1999; Cerdá et al., 2009; see also the review in Reeves and Moreau, 2019). It would be challenging to investigate the role of workers' traits and possible leadership in the process of group choice. In general, throughout different ant species, behavioral and cognitive individual variability is expressed to varying degrees in species and populations with different foraging systems.

As noted before, it is widely accepted that in eusocial insects, colony personality emerges from the workers' personalities (Pinter-Wollman, 2012; Jandt et al., 2014; Wright et al., 2019; Horna-Lowell et al., 2021). However, the eusocial characteristics of ants require a specific approach to the concept of personality. At the colony level, the term "colony personality" is not used to mean strong consistency of the collective actions over time and situations. Even within this framework of non-strict restrictions, I found only a few studies on the workers' personalities. Here I provide a detailed analysis of workers' behavioral and cognitive features in the context of various foraging styles that can provoke intriguing new questions and chart the directions for studying workers' personalities. 


\section{boq}
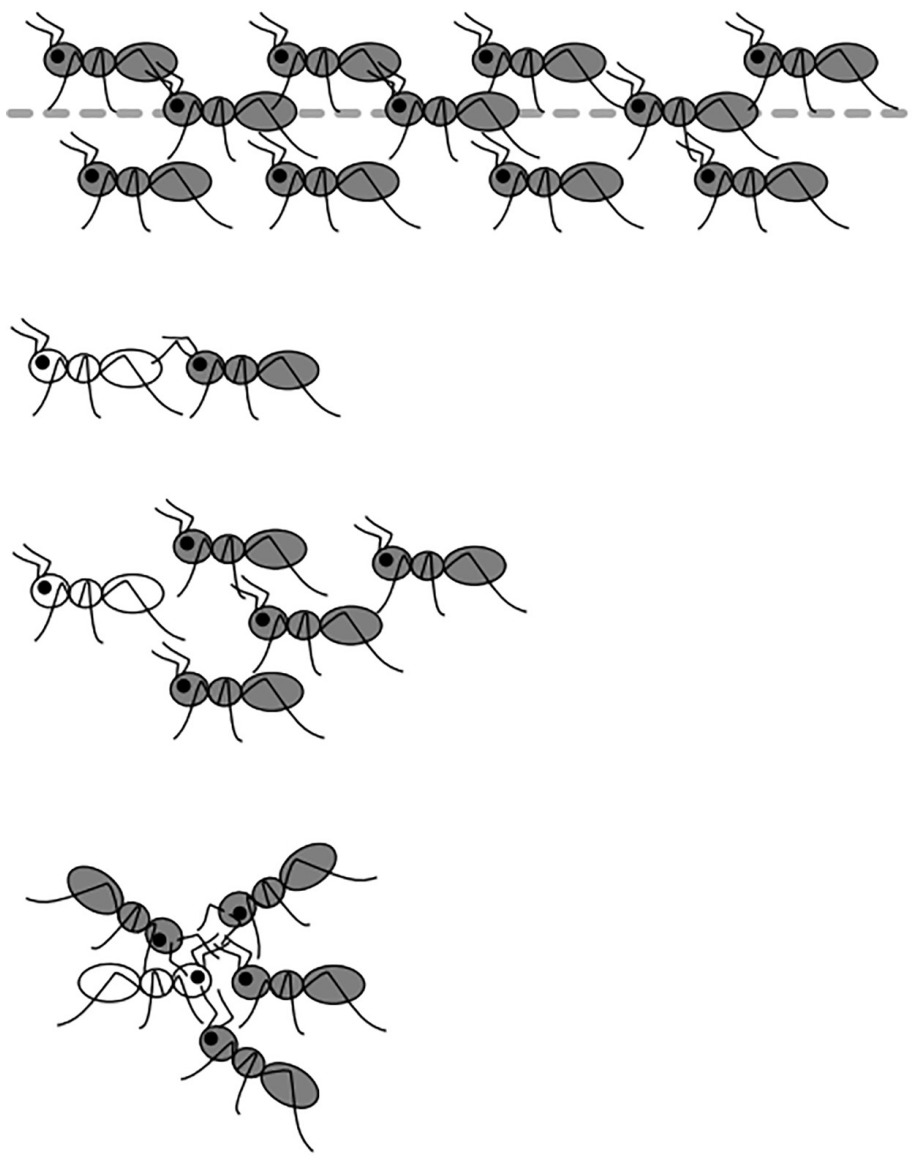

\section{Solitary foraging}

\author{
Mass recruitment
}

Tandem running

Group recruitment

\section{Leader-scouting}

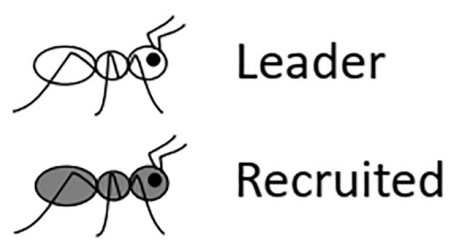

FIGURE 1 | Four main categories of recruitment strategy in ants: mass recruitment, tandem running, group-recruitment, and leader-scouting.

In workers' behavioral variability, a crucial question is what makes an ant a scout and to what extent the scout determines the collective foraging success. It is worth recalling that, in ant literature, scouting includes exploring and memorizing something about the outside world and recruiting nestmates by various means of information transfer, from trail laying to direct communications (Hölldobler and Wilson, 1990; Leonhardt et al., 2016; Kolay et al., 2020; Reznikova, 2020). In the general case, scouts are the first ants to leave the nest, discover a food source, and return to the nest with the food, before recruiting additional ants to forage (Simola et al., 2016). In many ant species, the communication of foraging information does not include "symbolic" components like in honeybees with their sophisticated dance-based recruiting system (von Frisch, 1967; Seeley, 2009). Instead, members of many species use odor trails and different forms of "invitations" transferred from the scouting individuals to the recruited ones (review in Reznikova, 2017). Honeybees use the availability of recruitment dances to decide whether to become a scout or a recruit. For a long time, it was believed that bees do not display a personal propensity to search activity (Beekman and Dussutour, 2009; Ratnieks and Shackleton, 2015). However, recent studies (Cook et al., 2019, 2020) report that underlying this division of labor is the essential difference in learning ability: scouts ignore familiar odors while recruits readily learn novel and familiar odors. Which traits underpin the division of labor between scouts and recruits in 
ants remains obscure in many aspects. I will try to analyze this fundamental problem further in this section.

\section{Behavioral and Cognitive Individual Variability in Solitary Foraging Ants}

This section starts with the group of solitary foraging species, although they display recruitment behavior very rarely. Instead, they use a simple rule based on the so-called encounter rate (Greene et al., 2013) to inform their nestmates about food. For example, in Cataglyphis niger individuals react to the speed of other ants that previously found a food source and thus change their behavior according to the states of others (Razin et al., 2013). Among solitary foraging species, the individual life history of ants of the genus Cataglyphis offers a unique experimental model as these ants meander foraging excursions reaching several hundreds of meters in length and have to learn much about the external world during a rather short life outside the nest (reviews in Wehner and Rössler, 2013; Pfeffer et al., 2020). Even being restricted by a limited period of out-nest activity of about 7 days (Fleischmann et al., 2016), Cataglyphis workers display significant behavioral variability. In C. cursor, only a third of the workers follow the classical age polyethism (Retana and Cerdá, 1991). Schmid-Hempel (1984) revealed individually expressed foraging methods in C. bicolor: foragers differ significantly in their persistence to re-search a find from a previous foraging excursion. The author suggested that the inter-individual behavioral differences could be caused by a training bias of the short-living foragers. However, to my knowledge, individual cognitive variability has not been studied yet in Cataglyphis species, although this group is very promising in this aspect.

Members of solitary foraging species of the subgenus Serviformica (sensu: Romiguier et al., 2018) such as F. cunicularia, F. rufibarbis, F. fusca, F. lemani and some others are known to be highly agile and explorative. Like Cataglyphis, these ants use the distant skyline and landmark cues for navigation, as that has been shown in field experiments on F. (Serviformica) japonica (Fukushi and Wehner, 2004). Field experiments revealed superb explorative and learning abilities in F. cunicularia compared to the mass-foraging species (Reznikova, 1982, 2018). Piqueret et al. (2019) have shown that F. fusca workers are capable of great learning and memory performances. Applying the associative learning paradigm, the authors demonstrated that ants learn very fast. Their memory is retained for up to 3 days and is highly resistant to extinction, even after a single conditioning trial.

As far as I know, the only study on personality in solitary foraging species used $F$. fusca workers to examine the relationship between individual and group behavioral phenotype (Carere et al., 2018). The authors tested Pinter-Wollman's (2012) hypothesis about worker personality as a measure of how a worker performs a task. They constructed homogenous groups of workers of known age and behavioral type, assessing their performance as a whole, and recording the individual behavior during the group performance. Experimental groups consisted of 6 individuals each, housed with 3 cocoons and a refuge. Individual exploratory activity appeared to be associated with the performance in cocoon recovery at the group level. Groups composed of highly exploratory ants started transporting displaced cocoons earlier and transported more cocoons than groups with less exploratory individuals. These results suggest that colony personality reflects the average personality of workers involved in a given task.

\section{Behavioral and Cognitive Individual Variability in Mass Recruiting Ants}

In mass recruitment systems, patterns of interactions among individuals are governed by rules of self-organization, and relatively simple units result in a sophisticated behavior at the group level. A common form of recruitment is broadcasting information through chemical trail communication. Carthy (1950) was one of the first to experimentally studying trail laying in ants. When workers find a food source, they feed and return to the nest laying a chemical trail secreted by specialized glands (Dlussky et al., 1978; Hahn and Maschwitz, 1985; Hölldobler and Wilson, 1990).

For example, in the black garden ant Lasius niger, a process of recruitment follows autocatalytic dynamics. When a colony is presented with two unequal food sources, scouts that find the better ones have a higher plausibility of laying a scent trail than scouts that find the less plentiful one. Recruits further build up the trails, also with a quality-dependent probability. Over time this differential positive feedback generates more effective trails, and stronger exploitation, at a better source (Beckers et al., 1993). Mailleux et al. (2011) found that $27 \%$ of starved workers who receive food from the scout relay the information by depositing a chemical signal themselves even before discovering and consuming the food source.

The Pharaoh ant, Monomorium pharaonis, possesses multicomponent pheromone system to recruit nestmates to a food source. Sudd (1960) was the first to describe the foraging system of this species. When a successful scout returned to the nest it activated a small group of nestmates. These recruits followed the odor trail laid by the scout, fed, and returned to the nest by the same trail, supporting it with a new scent. In the nest, they activated more recruits. Now it is known that trails are laid using two volatile, short-lived pheromones (a positive attractant and a negative, "no entry," pheromone) and a non-volatile, long-lived, attractant (positive) pheromone, which together allow the Pharaoh ant to efficiently exploit ephemeral food sources (Robinson et al., 2005; Jackson and Ratnieks, 2006). This system of trail following is much more complicated than that in another mass recruiting species, the fire ant, Solenopsis saevissima, which follows a pheromone that persists in the air, emanating from the volatile trail below and creating a cloud with the maximum radius of $1 \mathrm{~cm}$ (Wilson, 1962).

Price et al. (2016) presented the Pharaoh ants with the food sources of different qualities and found the differences in pheromones produced by individuals foragers. With two trails leading to high-quality food sources, both trails should be strongly marked. When two identical low-quality resources are available, individuals will mark a trail rather weakly and randomly, depending partly on their starvation level, as has 
been shown also in L. niger (Mailleux et al., 2011). Jackson et al. (2006) identified the individual behavioral specialization of $M$. pharaonis foragers, the position of their antennae, which mediated their ability to detect long-lived trails. Only $27.5 \%$ of foragers were highly successful, whereas others failed to detect the trail. Successful trail detection by M. pharaonis occurred only in foragers that held their antennae low and made frequent contacts with the substrate. The authors found that $17 \%$ of "pathfinder scouts" could locate and follow the long-lived trails, even after being fed.

Members of the genus Myrmica demonstrated the ability to switch between mass recruiting and group recruiting depending on the size of the food source (Dlussky et al., 1978; Cammaerts and Cammaerts, 1980; de Biseau et al., 1991) and intra- and interspecies hierarchical relations (Putyatina, 2007). Most often, Myrmica ants serve as an example of mass recruiting foraging mode (Vaes et al., 2020).

Even in mass recruiting species, with their seemingly impersonal actions, individual learning and exploratory activity can be important factors for the foraging success of the colony. The role of individual learning in the recruitment processes could be interpreted with respect to the species' behavioral ecology. Aron et al. (1993) compared individual learning abilities in two typical mass recruiting species, the black garden ant $L$. niger and Argentine ant Iridomyrmex humilis. While both species react to the trail pheromone, a large number of $L$. niger foragers switch promptly to the individual orientation, based on their memory of environmental cues. Argentine ants predominantly use collective chemical cues. Observations on individually marked foragers showed that nearly all the I. humilis foragers initially lay a trail, whereas only half the L. niger foragers do so. This proportion decreases considerably with the number of trips performed by L. niger workers while remaining constant for the Argentine ant. The individual spatial memory seems therefore to play a minor role in that species.

In general, despite much promising evidence of individual behavioral and learning variability in mass recruiting species, worker personality results are scarce. For example, L. niger, a model species for studying mass recruiting, is known as forming a collective personality, that is, consistent between-group differences in behavior (Jandt et al., 2014; Pasquier and Grüter, 2016). As far as I know, there are no studies on worker personality in Lasius. Myrmica seems to be the only group of mass recruiting species that has been studied before regarding personality traits both at individual and colony levels (Chapman et al., 2011; Pamminger et al., 2014, see details in the previous section).

\section{Behavioral and Cognitive Individual Variability in Tandem Running Ants}

Similar to mass recruiting, mobilizing nestmates to a food source through tandem running has an autocatalytic component. Tandem running is common in species with very small colonies (Beckers et al., 1989) and is prevalent across the ant phylogeny (review in Schultheiss et al., 2015). Möglich et al. (1974) discovered a special "tandem calling" signal in three Leptothorax species; the recruiter slants its gaster upward and discharges poison gland secretions from the extruded sting. Nestmates are attracted, and as soon as one of them touches the signaling individual, tandem running starts. The authors suggested that tandem running is the evolutionary precursor of odor-trail communication. In some species, the tandem running technique is only used during "house-hunting," whereas other species explore tandem running in both migration and foraging (review in Grüter et al., 2018). This recruitment system has been considered to be a primitive one since only one nestmate is recruited at a time. Tandem running seems to be costly for leaders, as the walking speed of followers is low compared to solitary foraging ants. For example, in the Brazil ponerine ant Pachycondyla harpax, ants are approximate to 66\% faster when traveling alone, and in the Australian "sugar ant" Camponotus consobrinus, foragers walking alone are about twice as fast (Schultheiss et al., 2015). Tandem runs are often unsuccessful, leaving followers in a potentially unknown or dangerous territory (Glaser and Grüter, 2018). For example, in P. harpax, if tandem runs break up (similar to $23 \%$ of all tandem runs), followers do not find the food and return to the nest (Grüter et al., 2018).

Significantly, individual learning increases the effectiveness of foraging based on tandem running. Studies on the rock ant Temnothorax albipennis (Franklin, 2014) and C. consobrinus (Schultheiss et al., 2015) demonstrated that the experience gained improves navigational success both for leaders and followers. In T. nylanderi, tandem run followers learn specific routes from their leaders: independent journeys back to the food source were significantly more similar to the routes on which the ants had been led, compared with the routes taken by other tandem runs (Sasaki et al., 2020). Glaser and Grüter (2018) found that in T. nylanderi the success rate $(75-86 \%)$ of tandem runs increases with the leader's experience, from $67 \%$ for the first tandem run to $94 \%$ for the fourth. Interestingly, 33\% of all tandem runs started with more than one follower, and $11 \%$ of all successful tandem runs reached the food source with more than one follower. That leaders can be followed by several ants, as the authors give this, support the Beckers et al. (1989) statement that the evolution of group recruitment from tandem running could be a small step.

Again, like in mass recruiting species, there is much promising evidence of the essential role of individual learning and behavioral variability in the success of foraging through tandem running. However, as far as I know, there are still no results on individual differences between leaders and followers. Although rock ants Temnothorax serve as one of the model groups for studying tandem running (Planqué et al., 2010), their personality traits have been examined before only at the colony level (Bengston and Dornhaus, 2014; Modlmeier et al., 2014; Lichtenstein et al., 2016) and not individually.

\section{Behavioral and Cognitive Individual Variability in Group Recruiting Ants}

In contrast to tandem-running, which is based on pair interactions between leaders and followers, and mass foraging that lacks true leadership, the group recruitment system includes scout leadership, which can be promising for studying worker personality manifestation. An individual who has discovered 
a new food source guides an audience of several nestmates using tactile stimulation or exciting movements. The leader then escorts a group of recruits until they reach the food source. Trail pheromones may provide the directional information and are unable to induce recruitment. In some species, such as Lasius fuliginosus (Hangartner, 1967), several Camponotus species (Hölldobler, 1971; Traniello, 1977, 1989; Hölldobler and Wilson, 1990, 2009), Tetramorium caespitum, and different members of the genus Polyrhachis (Hölldobler and Wilson, 1990), the mobilization of foragers to a food source displays the combination of chemical mass communication and the group recruitment technique. As already mentioned, some species can switch between the ways of foraging. A combination of group and mass recruitment were firstly found in several Myrmica species (Dlussky et al., 1978; de Biseau et al., 1991; Putyatina, 2007; Fedoseeva, 2015). The pavement ant T. caespitum, which also combines group and mass recruitment styles, can reallocate nestmates to a better food source while a colony is already exploring a source of mediocre quality. As soon as a scout has discovered the rich food source, it can guide foragers to that source via group recruitment. Individuals can modify the amount of pheromone they deposit, depending on the quality and quantity of the food (Verhaeghe, 1982). Such a dual mechanism, combining direct and indirect recruitment, contrasts to that of Lasius niger, which depends solely on mass recruitment and unable to relocate its foraging efforts (Beckers et al., 1989). The tree-dwelling African ant Polyrhachis laboriosa uses individual foraging when the food resource is small, whereas scouts apply group recruitment for large sources. In this case, the choice of the foraging strategy is determined by the first forager, which can flexibly switch its behavior depending on the size of the food supply (Mercier and Lenoir, 1999; review in Reeves and Moreau, 2019). There is evidence that Camponotus aethiops employs group recruitment, i.e., after having discovered a novel food source, a potential leader returns to the nest and attracts several recruits (1-20), which follow closely behind the leader to the food site (Suzzoni et al., 1991). In the gypsy ant Aphaenogaster senilis food availability (quality, quantity, transportability) also influences the decision-making process of workers changing from individual foraging to group recruitment (Cerdá et al., 2009). Although recruitment behaviors are uncommon among solitary foraging desert species such as Cataglyphis, Melophorus, and Ocymyrmex, field experiments revealed it in some of these species. Sommer et al. (2013) showed that in O. robustior, running at high speed to the rich food sources that may be more than 60 $\mathrm{m}$ apart from the nest, a leading ant is followed by a dispersed group of 2-7 recruits, which often lose contact and return to the nest. In spite of the rapid and often quite erratic looping behavior of the recruits, the recruiting process could be quite effective. The leader sometimes touches the surface of the ground with the tip of its gaster likely depositing a volatile pheromone signal. Marking the foraging ants, the authors revealed that the leaders were on average older than the recruits. Schultheiss and Nooten (2013) revealed group recruitment without pheromone trails in M. bagoti.

Since group recruitment includes targeting communication to a group of dedicated individuals, the question arises about leaders' personal features. Although many exciting results have been obtained during the last half-century on behavioral mechanisms of group recruitment, there are only a few, if any, evidence of ants' careers and behavioral consistency as leaders. I found only two studies on leaders' individual traits. Collignon and Detrain (2014) examined whether leaders evaluate their efficiency at transferring information to naive nestmates and change their behavior according to the audience size. In T. caespitum, a group leader does not pay attention to their followers during the foraging trip: it does not stop or decrease its walking speed to wait for lost recruits. However, some differences in the characteristics of leaders' trajectories seemed to influence their guiding efficiency. An eloquent example of leadership in group-recruiting species came from studying Formica schaufussi (Robson and Traniello, 2002). In this species, workers perform distinct roles during a single retrieval event that lasts about $30 \mathrm{~min}$. A scout that finds prey too large to retrieve individually recruits foragers to transport it. Scouts play a key role in maintaining the cohesion of the group members. If a scout is experimentally removed, the recruits typically leave the prey and cooperative foraging is finished. In this context, recruits are unable to perform as scouts and rearrange group transport. It is of particular interest that ants marked as recruits in one retrieval event can switch and act as scouts in subsequent retrievals. This "transient division of labor," as the authors give this, represents a distinct type of short-term individual specialization. Interestingly, in their review on the keystone individual concept, which explains the inordinate effect that some individuals exert on group dynamics and performance (sensu: Sih and Watters, 2005), Modlmeier et al. (2014) list the F. schaufussi case (Robson and Traniello, 2002) as a single example of the "organizing scouts" among social insects, and these authors assign to scouts of honeybees a more modest role of catalysts.

Recent studies support the hypothesis that group recruiting species, with their more flexible behavior and leadership, are promising for studying personality at the individual level. In carpenter ant $C$. aethiops, consistent individual differences in exploratory activity predict learning performance, with "activeexplorers" being slower in learning than "inactive-explorers" (Udino et al., 2017). d'Ettorre et al. (2017) studied the link between personalities and cognitive judgment bias in this species, the propensity to anticipate either positive or negative consequences in response to ambiguous information. Ants were trained to associate a particular spatial position to reinforcement and another position to a punishment. Once the ants learned this task, they were presented with a cognitive judgment bias with the stimulus in an intermediate position. Exploratory behavior, quantified with different open-field tests, varied among individuals, but it was consistent over time within individuals and thus met personality criteria. Fast explorers in the open-field took more time to approach the ambiguous stimulus compared to slow explorers. Maák et al. (2020) revealed a link between behavioral traits and tool use in A. senilis. This species has long been known as the user of debris to transport liquid food (Fellers and Fellers, 1976; reviews in Lörinczi et al., 2018; Maák et al., 2020). Maák et al. (2020) tested tool-using abilities in individuals using two tests, open-field and reaction to prey. The personality 
predicted the probability to perform tool use: ants that showed higher exploratory activity and were more attracted to prey in the personality tests readily became new tool users when previous tool users were removed from the group.

In sum, in most (though not all) tandem-running, massand group recruiting species, labor division between scouts and recruits is ephemeral. The current situation, and not life career, determine the ant's role as a potential leader. However, essential individual differences and behavioral and learning flexibility can be promising for studying worker personality, especially in group recruiting species. To date, data on personality at the individual level include group recruiting C. aethiops (d'Ettorre et al., 2017), Myrmica (Chapman et al., 2011; Pamminger et al., 2014) that can switch between mass- and group recruiting, and A. senilis (Maák et al., 2020) switching between solitary foraging and group recruiting.

\section{Behavioral and Cognitive Specialization in the "Leader-Scouting" Ant Species}

Until recently, the interplay between information transfer and worker personality remained completely unexplored. In the leader-scouting foraging system, the leadership is based on the permanent role of a scout as a "cognitive leader," who memorizes the way and shares information about remote targets using tactile contacts (antennation) with the members of a constant group of foragers. No other cues such as chemical trails or direct guiding are required for recruitment (see detailed reviews in Reznikova, 2008, 2020). This system has been revealed in several species belonging to the Formica rufa group (red wood ants) (Reznikova and Ryabko, 1994, 2011). In comparison with many sympatric species, the mound-building red wood ants have hundreds of times more individuals in their colonies and vast feeding territories (Dlussky, 1967; Rosengren and Sundström, 1987).

As demonstrated recently (Reznikova, 2020), solitary foraging and leader-scouting ants although strikingly different in their social and ecological particularities, have many common features of learning and orientation. There is much evidence of long-term lasting storage of visual memory in red wood ants (genus Formica) (Rosengren, 1977; Fourcassie and Beugnon, 1988; Nicholson et al., 1999; Salo and Rosengren, 2001). Laboratory experiments have revealed outstanding visual landmark memories in Formica (Graham and Collett, 2002; Harris et al., 2005; Fernandes et al., 2015), in contrast to mass recruiting L. niger ants, which learn odor associations faster than visual cues (Oberhauser et al., 2019). It is worth noting that in all experiments on learning and memory cited here, red wood ants have been considered regardless of their task-group affiliation. However, as shown below, specific individual differences in orientation and cognition in these species are determined precisely by their role in society.

It was demonstrated in early studies that in Formica s. str., out-nest workers include hunters and collectors of nest material operating on the ground, aphid milkers collecting honeydew within the tree crowns, hunters acting on the trees, and guards defending the nest entrances (Otto, 1958; Horstmann, 1973). Investigations at the individual level revealed essential behavioral differences between members within various task groups. For instance, the task group of aphid tenders includes "professional" subgroups such as scouts, aphid milkers ("shepherds"), aphid guards, and carriers (Reznikova and Novgorodova, 1998; Reznikova, 2007; Novgorodova, 2015). Experimental studies of interactions of $F$. aquilonia with ground beetles, showed that nest guards and hunters are significantly more aggressive than aphid milkers toward these large and dangerous enemies (Reznikova and Dorosheva, 2004, 2013; Dorosheva et al., 2011). Experiments with other intruders, such as spiders and parasitic rove beetle, revealed a context-dependent specialization in colony defense in F. rufa: small workers were better at preventing brood predation than larger workers, and nurses and workers at nest entrances were more aggressive toward parasitic beetles than foragers (Parmentier et al., 2015). Recently, Iakovlev and Reznikova (2019) showed that in red wood ants F. aquilonia, members of various professional groups form aversive associations with different strengths and speeds. The authors examined whether hunters and aphid milkers learn to avoid the irritating encounters with their enemy (hoverfly larvae) differently. They then analyzed the difference between learning in "wild" and laboratory-reared (naïve) foragers. During the first interaction with the enemy, the naïve ants displayed a higher level of aggressiveness than the natural colony members. The aphid milkers, who had a negative experience of encounters with the larvae, being "glued" with their viscous secretion, behaved essentially less aggressively even after 3 days, thus displaying the formation of longlasting memories. The authors suggest the difference in learning capacities between aphid milkers, hunters, and guards caused by cognitive specialization within Formica colonies. Together with examples on Myrmica (Chapman et al., 2011; Pamminger et al., 2014), whose worker personalities are related to task allocation (behavioral poyethism), these examples on Formica s.str. may satisfy the "task syndrome" concept recently suggested by Loftus et al. (2021) to explain the personality phenomenon in eusocial insects. However, here I am trying to consider personalities of workers as full-fledged members of eusocial societies.

Long-term experiments on "ants language" (reviews in Reznikova, 2017, 2020) have provided much evidence that in leader-scouting ants, navigation and learning essentially differ between various task groups depending on their cognitive specialization (sensu: Reznikova, 2007). In honeybees, scouts transfer highly accurate locational information through the well-known waggle dance, which codes for both distance and direction of food sources (Leadbeater and Chittka, 2007). Similarly, in red wood ants, scouts transfer quantitative information about the location of a goal to recruits through direct interactions (Reznikova and Ryabko, 2011). To perform symbolic communication, Formica ants use antennal interaction patterns. However, unlike honeybees, in which the decision to be a scout is determined mainly by the current motivation (Beekman and Dussutour, 2009; Ratnieks and Shackleton, 2015), red wood ants display consistent roles based on the behavioral and cognitive difference between scouting and recruiting individuals (Reznikova, 2007, 2008). It is worth noting that only a rather primitive mode of recruitment, called "kinopsis" (Stüger, 1931; Dlussky, 1967; Reznikova, 1982) or "directional recruitment" 
(Rosengren and Fortelius, 1987), have been described in red wood ants before. During directional recruitment, scouts attracted workers roaming in the vicinity by making alerting movements upon finding food. Tanner (2009) also found that in F. integroides, foragers weakly recruit nestmates to newly discovered resources.

A relevant situation for studying the individual distribution of roles when performing a cooperative task is a honeydew collection by foragers in the tree crown. The intricate details of task distribution among honeydew collectors remained obscure. The duty includes finding a new aphid colony, informing other ants about the goal, and organizing the honeydew collection and its transportation to the nest. Laboratory experiments based on the "binary tree" paradigm simulating informative contacts between scouts and aphid milkers (foragers) revealed a sophisticated ant "language." During experiments, in each trial, one scout (revealed and marked in the preliminary phase of experiments) was placed on the binary tree leaf that contained food and could then return to the nest. Each scout transferred messages to a small (five animals on average) constant group of recruits and did not contact members of other groups. The scout contacted foragers one by one, or, sometimes, two of them simultaneously. It is important to note that in total, 335 scouts and their groups took part in the experiments. The composition of groups remained constant in each colony from several days to several weeks, that is, during periods when a given scout was actively working. In contrast to F. schaufussi, with their "transient division of labor" (Robson and Traniello, 2002), members of Formica s.str. species never switched their roles as scouts and recruits. Instead, long-term studies showed that cognitive responsibilities are strongly distributed between scouts and recruited foragers. Scouts can recognize regularities in the sequences of turns (right and left) in the "binary tree" maze returning to the nest, and use them to optimize their messages to the recruits, whereas the foragers can only memorize and not transfer the information (see details in Reznikova, 2008, 2017, 2020). We thus can suggest that red wood ants possess personalized teams as functional structures within their colonies. Although there is some evidence of social insects' ability to recognize each other individually (Tibbetts, 2002; d'Ettorre and Heinze, 2005; Sheehan and Tibbetts, 2011), we did not find signs of individual recognition in the context of foraging in ants and additional experiments are needed to elucidate this answer.

With such a dramatic functional difference between task groups in Formica s.str. species, it is challenging to compare their behavioral and cognitive differences. Atsarkina et al. (2014) designed a battery of behavioral tests to investigate personal characteristics in members of various professional groups: scouts, shepherds, guards, and foragers. The levels of aggression were measured by recording behaviors during encounters with ground beetles (for details, see Reznikova and Dorosheva, 2004, 2013). Exploratory activities were quantified by evaluating time spent by ants on plastic models simulating pieces of nature ("the artificial world") such as stones, tree trunks, and grass stems. Spatial cognition was assessed as the ability to memorize the sequences of turns in a binary tree maze (for details of the whole experiment, see also Reznikova, 2017). Both scouts and foragers appeared to display much more active exploration than other ants, and scouts more so than foragers. In "the artificial world," scouts switched more willingly between different kinds of activities. Scouts and foragers demonstrated nearly equal levels of aggressiveness, more than shepherds and closer to guards, but never attacked dangerous enemies directly. The most characteristic feature of scouts was their high activity in the examination of new items. Scouts also form spatial memory faster and keep memories longer and more precisely than foragers.

In sum, unique life-history features of Formica s.str. ants favor cognitive specialization within their societies. This specialization may be based on the ability of certain individuals to learn faster within specific domains. Red wood ants' abilities to encode sequences of turns along their way to a goal can be considered a cognitive adaptation to their specific foraging style within the tree crown. The leader-scouting seems to be the only foraging system based on consistent personal differences between scouting and foraging individuals.

\section{FUTURE DIRECTIONS}

During the last two decades, the field of comparative personality study has acquired data on numerous and highly diverse invertebrate taxa, mainly arthropods. However, so far only a few empirical works have investigated insects' multiple behavioral dimensions, and the research on insect personality in the field is still scarce. Studying ants gives researchers good opportunities to understand the role of cognitive abilities and social contexts in driving and maintaining animal personalities. There is a growing interest in exploring the interplay between information used by individuals and groups in ants. One of the main problems is understanding how the distribution of individual behavioral traits and cognitive responsibilities within ant colonies depends on the species' foraging style. Here I highlight several avenues for further research that will help us elucidate the extent to which collective cognition is individual-based in ants and whether a single individual's actions can direct the entire colony or colony units.

(1) In ant personality literature, most works are about personality at the colony level, which can possibly be attributed to the "super-organism" mindset popularized during the last decades. In this context, the term "colony personality" is not used to mean strong consistency of the colony's collective actions over time and situations but rather consistency of a set of certain properties. Within this framework of non-strict restrictions, many exciting results have been obtained at the colony level on behavioral axes such as boldness, explorativeness, and reactions to various environmental changes. However, although "colony personality" studies include different ant species (reviews in Wright et al., 2019; Horna-Lowell et al., 2021), most of them consider rock ants Temnothorax as a model to describe holistic behaviors of ant communities. Since rock ants, with their smallsize colonies and relatively narrow ecological niches, use a relatively simple task system and foraging style, this model is not sufficient for understanding how collective behaviors emerge and function at the colony level. It is worthy of nothing that 
inter-colony differences in cognitive coping styles remain so far obscure. Further studies on different species are required to understand how individual learning abilities could determine the colonies' efficiency at performing particular tasks.

(2) In monomorphic ant species, nestmate workers' behavioral and cognitive variability is expressed to varying degrees in species and populations with different foraging systems. However, variability in individual performance is not sufficient to conclude personality. There is much evidence that the role of individual learning and behavioral variability in foraging based on tandemrunning, mass- and group recruiting systems is significant, which makes these systems promising for studying worker personalities. However, to date, among species with mobilization systems, data on personality at the individual level include only three cases: group recruiting C. aethiops (d'Ettorre et al., 2017), Myrmica (Chapman et al., 2011; Pamminger et al., 2014) that can switch between mass- and group recruiting, and A. senilis (Maák et al., 2020) switching between solitary foraging and group recruiting. Surprisingly, solitary foraging ants, with their good learning abilities and essential individual variability, poorly studied in the context of personality. The only study on personality in solitary foraging F. fusca (Carere et al., 2018) explores their individual exploratory activity associated with the performance in cocoon recovery.

(3) In the context of how ants' personalities display during foraging, a crucial question is what makes an ant a scout that discovers a new food source and mobilizes its nestmates. The analysis of ant literature shows that mass recruiting and tandem running systems do not display substantial lifelong distinction among different foraging roles. Since the task fidelity is weak in all these species, as far as I know, there are still no results on individual differences between leaders and followers. Even in group-recruiting species, with their targeted communication between recruiters and recruited nestmates, there are only a few, if any, evidence of ants' careers and behavioral consistency as leaders. Personal traits characterize groups of individuals at the colony level, but not performers of functional roles during group-recruiting foraging. Further research is required to capture the relationship between individual foraging strategies and personalities in species with different mobilization styles.

(4) Although animal personality is a trendy area covering more and more species and behavioral aspects, only a few works try to determine whether ants show consistent withinspecies between-individual variation in cognitive abilities. In ants, the interplay between information transfer, cognition, and personality at the individual level remains completely

\section{REFERENCES}

Aron, S., Beckers, R., Deneubourg, J. L., and Pasteels, J. M. (1993). Memory and chemical communication in the orientation of two mass-recruiting ant species. Insect. Soc. 40, 369-380.

Atsarkina, N. V., Iakovlev, I. K., and Reznikova, Z. (2014). Individual behavioural features of scouts and recruits in red wood ants (Hymenoptera:Formicidae). Euroas. Entomol. J. 13, 209-218.

Beckers, R., Deneubourg, J. L., and Goss, S. (1993). Modulation of trail laying in the ant Lasius niger (Hymenoptera: Formicidae) and its role in the collective unexplored. When a scout shares information about remote targets with the members of a constant group of foragers, the leader-scouting foraging system seems to be the only one for which individual behavioral and cognitive differences play a crucial role in the colony's coping style. Applying the new battery of tests, Atsarkina et al. (2014) revealed consistent behavioral and cognitive differences between scouts and other functional groups, which can be attributed to personalities. The essential feature underpinning the leader-scouting system is the constancy of scouts and foragers enshrined in their life careers. I suggest considering other species possessing the leader-scouting foraging system and find carpenter ants Camponotus promising in this context. C. herculeanus demonstrated information transmission between scouts and foragers, where the information was about food placed on one of the 12 branches of one out of 10 artificial "trees" (details in Reznikova, 1983, 2017). One colony were tested on the binary tree maze and displayed the rate of information transmission comparable with red wood ants F. polyctena. However, in contrast to red wood ants, with their 8-9 scout-forager working team visiting the maze during the day, only one team per day acted in carpenter ants (Reznikova and Ryabko, 1994). The new data on the link between personality and cognitive skills in the carpenter ant C. aethiops (d'Ettorre et al., 2017) makes this group of species prospective candidates for studying cognitive specialization within colonies.

\section{AUTHOR CONTRIBUTIONS}

The author confirms being the sole contributor of this work and has approved it for publication.

\section{FUNDING}

This work was funded by Russian Fund for Basic Research (No. 20-04-00072) and by the Federal Fundamental Scientific Research Program (FWGS-0247-2021-0003).

\section{ACKNOWLEDGMENTS}

I am grateful to Daniil Ryabko for the helpful discussion and useful comments. I thank Ivan Iakovlev for the drawing. I appreciate the efforts and valuable comments of three reviewers that helped me to improve the manuscript.

selection of a food source. J. Insect Behav. 6, 751-759. doi: 10.1007/BF0120 1674

Beckers, R., Goss, S., Deneubourg, J. L., and Pasteels, J. M. (1989). Colony size, communication and ant foraging strategy. Psyche 96, 239-256. doi: 10.1155/ $1989 / 94279$

Beekman, M., and Dussutour, A. (2009). "How to tell your mates: costs and benefits of different recruitment mechanisms," in Food Exploitation by Social Insect: Ecological, Behavioral and Theoretical Approaches, eds S. Jarau and M. Hrncir (Boca Raton, FL: CRC Press), $115-134$. 
Beekman, M., and Jordan, L. A. (2017). Does the field of animal personality provide any new insights for behavioral ecology? Behav. Ecol. 28, 617-623. doi: 10.1093/beheco/arx022

Bell, A. M. (2007). Future directions in behavioural syndromes research. Proc. Roy. Soc. B. Biol. Sci. 274, 755-761. doi: 10.1098/rspb.2006.0199

Bell, A. M. (2017). There is no special sauce: a comment on Beekman and Jordan. Behav. Ecol. 28, 626-627. doi: 10.1093/beheco/arx031

Bell, A. M., Hankison, S. J., and Laskowski, K. L. (2009). The repeatability of behaviour: a meta-analysis. Anim. Behav. 77, 771-783. doi: 10.1016/j.anbehav. 2008.12.022

Bengston, S. E. (2018). Life-history and behavioral trait covariation across 3 years in Temnothorax ants. Behav. Ecol. 29, 1494-1501. doi: 10.1093/beheco/ary101

Bengston, S. E., and Dornhaus, A. (2014). Be meek or be bold? A colony-level behavioural syndrome in ants. Proc. Roy. Soc. B. Biol. Sci. 281:20140518. doi: 10.1098/rspb.2014.0518

Bengston, S. E., Shin, M., and Dornhaus, A. (2017). Life-history strategy and behavioral type: risk-tolerance reflects growth rate and energy allocation in ant colonies. Oikos 126, 556-564. doi: 10.1111/oik.03527

Bergmüller, R. (2010). "Animal personality and behavioural syndromes," in Animal Behaviour: Evolution and Mechanisms, ed. P. Kappeler (Berlin: Springer Science \& Business Media), 587-621. doi: 10.1007/978-3-642-02624-9_19

Blight, O., Villalta, I., Cerdá, X., and Boulay, R. (2016). Personality traits are associated with colony productivity in the gypsy ant Aphaenogaster senilis. Behav. Ecol. Sociobiol. 70, 2203-2209. doi: 10.1007/s00265-016-2224-x

Bolton, B. (2020). AntWeb: Ants of Bolton World Catalog. Available online at: https: //www.antweb.org/project.do?name=worldants (accessed February 5, 2020).

Boomsma, J. J., and Gawne, R. (2018). Superorganismality and caste differentiation as points of no return: how the major evolutionary transitions were lost in translation. Biol. Rev. 93, 28-54. doi: 10.1111/brv.12330

Brodin, T. (2009). Behavioral syndrome over the boundaries of life-carryovers from larvae to adult damselfly. Behav. Ecol. 20, 30-37. doi: 10.1093/beheco/arn111

Budaev, S. (1998). How many dimensions are needed to describe temperament in animals: a factor re-analysis of two data sets. Int. J. Comp. Psychol. 11, 17-29.

Buechel, S. D., and Schmid-Hempel, P. (2016). Colony pace: a life-history trait affecting social insect epidemiology. Proc. Roy. Soc. B. Biol. Sci. 283, 20151919. doi: 10.1098/rspb.2015.1919

Calcraft, P. R. T., Bell, A. T., Husbands, P., Philippides, A., and Niven, J. E. (2016). The evolution of handedness: why are ant colonies left-and right-handed? Biomath Commun. 3:589. doi: 10.11145/589

Cammaerts, M. C., and Cammaerts, R. (1980). Food recruitment strategies of the ants Myrmica sabuleti and Myrmica ruginodis. Behavi. Proc. 5, 251-270. doi: 10.1016/0376-6357(80)90006-6

Canciani, M., Arnellos, A., and Moreno, A. (2019). Revising the superorganism: an organizational approach to complex eusociality. Front. Psychol. 10:2653. doi: $10.3389 /$ fpsyg. 2019.02653

Careau, V., Thomas, D., Humphries, M. M., and Réale, D. (2008). Energy metabolism and animal personality. Oikos 117, 641-653. doi: 10.1111/j.00301299.2008.16513.x

Carere, C., Audebrand, C., Rödel, H. G., and d'Ettorre, P. (2018). Individual behavioural type and group performance in Formica fusca ants. Behav. Proc. $157,402-407$.

Carthy, J. D. (1950). Odour trails of Acanthomyops fuliginosus. Nature. 166, 154. doi: $10.1038 / 166154 \mathrm{a} 0$

Cerdá, X., Angulo, E., Boulay, R., and Lenoir, A. (2009). Individual and collective foraging decisions: a field study of worker recruitment in the gypsy ant Aphaenogaster senilis. Behav. Ecol. Sociobiol. 63, 551-562. doi: 10.1007/s00265008-0690-5

Chapman, B. B., Thain, H., Coughlin, J., and Hughes, W. O. (2011). Behavioural syndromes at multiple scales in Myrmica ants. Anim. Behav. 82, 391-397. doi: 10.1016/j.anbehav.2011.05.019

Charbonneau, D., Sasaki, T., and Dornhaus, A. (2017). Who needs "lazy" workers? Inactive workers act as a "reserve" labor force replacing active workers, but inactive workers are not replaced when they are removed. PLoS One 12:e0184074. doi: 10.1371/journal.pone.0184074

Collignon, B., and Detrain, C. (2014). Accuracy of leadership and control of the audience in the pavement ant Tetramorium caespitum. Anim. Behav. 92, 159-165. doi: 10.1016/j.anbehav.2014.03.026
Cook, C. N., Lemanski, N. J., Mosqueiro, T., Gadau, J., Ozturk, C., Pinter-Wollman, N., et al. (2019). Heritable learning phenotypes drive collective cognition. BioRxiv [Prepprint]. doi: 10.1101/761676

Cook, C. N., Lemanski, N. J., Mosqueiro, T., Ozturk, C., Gadau, J., Pinter-Wollman, N., et al. (2020). Individual learning phenotypes drive collective behavior. Proc. Natl. Acad. Sci. U.S.A. 117, 17949-17956. doi: 10.1073/pnas.192055 4117

Corona, M., Libbrecht, R., and Wheeler, D. E. (2016). Molecular mechanisms of phenotypic plasticity in social insects. Cur. Opin. Insect Sci. 13, 55-60. doi: 10.1016/j.cois.2015.12.003

d'Ettorre, P., and Heinze, J. (2005). Individual recognition in ant queens. Cur. Biol. 15, 2170-2174. doi: 10.1016/j.cub.2005.10.067

d'Ettorre, P., Carere, C., Demora, L., Le Quinquis, P., Signorotti, L., and Bovet, D. (2017). Individual differences in exploratory activity relate to cognitive judgement bias in carpenter ants. Behav. Proc. 134, 63-69. doi: 10.1016/j.beproc. 2016.09.008

de Biseau, J. C., and Pasteels, J. M. (1994). Regulated food requirement through individual behaviour of scouts in the ant, Myrmica sabuleti (Hymenoptera: Formicidae). J. Insect Behav. 7, 767-777.

de Biseau, J. C., Deneubourg, J. L., and Pasteels, J. M. (1991). Collective flexibility during mass recruitment in the ant Myrmica sabuleti (Hymenoptera: Formicidae). Psyche 98, 323-336. doi: 10.1155/1991/38402

Dlussky, G. M. (1967). Ants of the Genus Formica (Hymenoptera, Formicidae). Biology, Practical Importance and Use, Keys for the Species Founded in USSR [in Russian]. Moscow: Nauka.

Dlussky, G. M., Voltsit, O. V., and Sulkhanov, A. V. (1978). Organization of group foraging in ants of the genus Myrmica. Zool. Jh. 57, 65-77, [In Russian with English summary].

Dornhaus, A. (2008). Specialization does not predict individual efficiency in an ant. PLoS Biol. 6:e285. doi: 10.1371/journal.pbio.0060285

Dorosheva, E. A., Yakovlev, I. K., and Reznikova, Z. I. (2011). An innate template for enemy recognition in red wood ants. Entomol. Rev. 91, 274-280. doi: 10. 1134/S0013873811020151

Drent, P. J., Oers, K. V., and Noordwijk, A. J. V. (2003). Realized heritability of personalities in the great tit (Parus major). Proc. Roy. Soc. B. Biol. Sci. 270, 45-51. doi: 10.1098/rspb.2002.2168

Emerson, A. E. (1939). Social coordination and the Superorganism. Am. Midl. Nat. 21, 182-209. doi: $10.2307 / 2420380$

Eyer, P. A., Freyer, J., and Aron, S. (2013). Genetic polyethism in the polyandrous desert ant Cataglyphis cursor. Behav. Ecol. 24, 144-151. doi: 10.1093/beheco/ $\operatorname{ars} 146$

Fedoseeva, E. B. (2015). A technological approach to the description of group foraging in the ant Myrmica rubra. Entomol. Rev. 95, 984-999. doi: 10.1134/ S0013873815080060

Feinerman, O., and Korman, A. (2017). Individual versus collective cognition in social insects. J. Exp. Biol. 220, 73-82. doi: 10.1242/jeb.143891

Fellers, J. H., and Fellers, G. M. (1976). Tool use in a social insect and its implications for competitive interactions. Science 192, 70-72. doi: 10.1126/ science.192.4234.70

Fernandes, A. S. D., Philippides, A., Collett, T. S., and Niven, J. E. (2015). Acquisition and expression of memories of distance and direction in navigating wood ants. J. Exp. Biol. 218, 3580-3588. doi: 10.1242/jeb.125443

Fleischmann, P. N., Christian, M., Müller, V. L., Rössler, W., and Wehner, R. (2016). Ontogeny of learning walks and the acquisition of landmark information in desert ants, Cataglyphis fortis. J. Exp. Biol. 219, 3137-3145. doi: 10.1242/jeb. 140459

Fourcassie, V., and Beugnon, G. (1988). How do red wood ants orient when foraging in a three dimensional system? I. Laboratory experiments. Insect. Soc. 35, 92-105. doi: 10.1007/BF02224142

Franklin, E. L. (2014). The journey of tandem running: the twists, turns and what we have learned. Insect. Soc. 61, 1-8. doi: 10.1007/s00040-013-0325-3

Frasnelli, E., and Vallortigara, G. (2018). Individual-level and population-level lateralization: two sides of the same coin. Symmetry 10:739. doi: 10.3390/ sym10120739

Friedman, D. A., Johnson, B. R., and Linksvayer, T. A. (2020a). Distributed physiology and the molecular basis of social life in eusocial insects. Horm. Behav. 122:104757. doi: 10.1016/j.yhbeh.2020.104757 
Friedman, D. A., York, R. A., Hilliard, A. T., and Gordon, D. M. (2020b). Gene expression variation in the brains of harvester ant foragers is associated with collective behavior. Commun. Biol. 3, 1-9. doi: 10.1038/s42003-020-0813-8

Fukushi, T., and Wehner, R. (2004). Navigation in wood ants Formica japonica: context dependent use of landmarks. J. Exp. Biol. 207, 3431-3439. doi: 10.1242/ jeb. 01159

Giraldo, Y. M., and Traniello, J. F. (2014). Worker senescence and the sociobiology of aging in ants. Behav. Ecol. Sociobiol. 68, 1901-1919. doi: 10.1007/s00265-0141826-4

Glaser, S. M., and Grüter, C. (2018). Ants (Temnothorax nylanderi) adjust tandem running when food source distance exposes them to greater risks. Behav. Ecol. Sociobiol. 72:40. doi: 10.1007/s00265-018-2453-2

Gordon, D. M. (2016). From division of labor to the collective behavior of social insects. Behav. Ecol. Sociobiol. 70, 1101-1108. doi: 10.1007/s00265-015-2045-3

Gordon, D. M. (2019). The ecology of collective behavior in ants. Annu. Rev. Entomol. 64, 35-50. doi: 10.1146/annurev-ento-011118-111923

Gosling, S. D. (2001). From mice to men: what can we learn about personality from animal research? Psychol. Bull. 127, 45-86. doi: 10.1037/0033-2909.127.1.45

Graham, P., and Collett, T. S. (2002). View-based navigation in insects: how wood ants (Formica rufa L.) look at and are guided by extended landmarks. J. Exp. Biol. 205, 2499-2509.

Greene, M. J., Pinter-Wollman, N., and Gordon, D. M. (2013). Interactions with combined chemical cues inform harvester ant foragers' decisions to leave the nest in search of food. PLoS One 8:e52219. doi: 10.1371/journal.pone.0052219

Griffin, A. S., Guillette, L. M., and Healy, S. D. (2015). Cognition and personality: an analysis of an emerging field. Trends Ecol. Evol. 30, 207-214. doi: 10.1016/j. tree.2015.01.012

Grüter, C., Wüst, M., Cipriano, A. P., and Nascimento, F. S. (2018). Tandem recruitment and foraging in the ponerine ant Pachycondyla harpax (Fabricius). Neotrop. Entomol. 47, 742-749. doi: 10.1007/s13744-017-0571-6

Gyuris, E., Feró, O., and Barta, Z. (2012). Personality traits across ontogeny in firebugs Pyrrhocoris apterus. Anim. Behav. 84, 103-109. doi: 10.1016/j.anbehav. 2012.04.014

Hahn, M., and Maschwitz, U. (1985). Foraging strategies and recruitment behaviour in the European harvester ant Messor rufitarsis (F.). Oecologia 68, 45-51. doi: 10.1007/BF00379472

Hamilton, A., and Fewell, J. (2013). "Groups, individuals, and the emergence of sociality: the case of division of labor," in From Groups to Individuals: Evolution and Emerging Individuality, eds F. Bouchard and P. Huneman (Cambridge, MA: MIT Press), 175-184.

Hamilton, W. D. (1964a). The genetical evolution of social behaviour I. J. Theor. Biol. 7, 1-16. doi: 10.1016/0022-5193(64)90038-4

Hamilton, W. D. (1964b). The genetical evolution of social behaviour II. J. Theor. Biol. 7, 17-52. doi: 10.1016/0022-5193(64)90039-6

Hangartner, W. (1967). Spezifität und inaktivierung des spurpheromons von Lasius fuliginosus Latr. und orientierung der arbeiterinnen im duftfeld. Zeitschr. Vergleich. Physiol. 57, 103-136. doi: 10.1007/BF00303068

Harris, R. A., de Ibarra, N. H., Graham, P., and Collett, T. S. (2005). Priming of visual route memories. Nature 438:302. doi: 10.1038/438302a

Hedrick, A. V., and Kortet, R. (2012). Sex differences in the repeatability of boldness over metamorphosis. Behav. Ecol. Sociobiol. 66, 407-412. doi: 10.1007/s00265011-1286-Z

Heinze, J. (2008). The demise of the standard ant (Hymenoptera: Formicidae). Myrm. News. 11, 9-20.

Helanterä, H. (2016). An organismal perspective on the evolution of insect societies. Front. Ecol. Evol. 4:6. doi: 10.3389/fevo.2016.00006

Hölldobler, B. (1971). Recruitment behavior in camponotus socius (hym. formicidae). Zeitschr. Vergleich. Physiol. 75, 123-142. doi: 10.1007/BF00335259

Hölldobler, B., and Wilson, E. O. (1990). The Ants. Cambridge, MA: Harvard University Press. doi: 10.1046/j.1420-9101.1992.50101-69.x

Hölldobler, B., and Wilson, E. O. (2009). The Superorganism: The Beauty, Elegance, and Strangeness of Insect Societies. New York, NY: WW Norton \&Company.

Horna-Lowell, E., Neumann, K. M., O'Fallon, S., Rubio, A., and Pinter-Wollman, N. (2021). Personality of ant colonies (Hymenoptera: Formicidae) - underlying mechanisms and ecological consequences. Myrm. News 31, 47-59. doi: 10. 25849/myrmecol.news_031:047
Horstmann, K. (1973). Untersuchungen zur arbeitsteilung unter den Außendienstarbeiterinnen der waldameise Formica polyctena Foerster. Zeitschr. Tierpsychol. 32, 532-543. doi: 10.1111/j.1439-0310.1973.tb01122.x

Iakovlev, I., and Reznikova, Z. (2019). Red wood ants display natural aversive learning differently depending on their task specialization. Front. Psychol. 10:710. doi: 10.3389/fpsyg.2019.00710

Jackson, D. E., and Ratnieks, F. L. (2006). Communication in ants. Curr. Biol. 16, 570-574. doi: 10.1016/j.cub.2006.07.015

Jackson, D. E., Martin, S. J., Holcombe, M., and Ratnieks, F. L. (2006). Longevity and detection of persistent foraging trails in Pharaoh's ants, Monomorium pharaonis (L.). Anim. Behav. 71, 351-359. doi: 10.1016/j.anbehav.2005. 04.018

Jandt, J. M., Bengston, S., Pinter-Wollman, N., Pruitt, J. N., Raine, N. E., Dornhaus, A., et al. (2014). Behavioural syndromes and social insects: personality at multiple levels. Biol. Rev. 89, 48-67. doi: 10.1111/brv.12042

Keller, L. (1995). Social life: the paradox of multiple-queen colonies. Trends Ecol. Evol. 10, 355-360. doi: 10.1016/S0169-5347(00)89133-8

Kolay, S., Boulay, R., and d'Ettorre, P. (2020). Regulation of ant foraging: a review of the role of information use and personality. Front. Psychol. 11:734. doi: 10.3389/fpsyg.2020.00734

Kortet, R., and Hedrick, A. N. N. (2007). A behavioural syndrome in the field cricket Gryllus integer: intrasexual aggression is correlated with activity in a novel environment. Biol. J. Linn. Soc. 91, 475-482. doi: 10.1111/j.1095-8312. 2007.00812.x

Kralj-Fišer, S., and Schuett, W. (2014). Studying personality variation in invertebrates: why bother? Anim. Behav. 91, 41-52. doi: 10.1016/j.anbehav. 2014.02.016

Labaude, S., O'Donnell, N., and Griffin, C. T. (2018). Description of a personality syndrome in a common and invasive ground beetle (Coleoptera: Carabidae). Sci. Rep. 8, 1-8. doi: 10.1038/s41598-018-35569-z

Lanan, M. (2014). Spatiotemporal resource distribution and foraging strategies of ants (Hymenoptera: Formicidae). Myrm. News. 20, 53-70.

Leadbeater, E., and Chittka, L. (2007). Social learning in insects-from miniature brains to consensus building. Cur. Boil. 17, R703-R713. doi: 10.1016/j.cub.2007. 06.012

Leonhardt, S. D., Menzel, F., Nehring, V., and Schmitt, T. (2016). Ecology and evolution of communication in social insects. Cell. 164, 1277-1287. doi: 10. 1016/j.cell.2016.01.035

Lichtenstein, J. L., Pruitt, J. N., and Modlmeier, A. P. (2016). Intraspecific variation in collective behaviors drives interspecific contests in acorn ants. Behav. Ecol. 27, 553-559. doi: 10.1093/beheco/arv188

Loftus, J. C., Perez, A. A., and Sih, A. (2021). Task syndromes: linking personality and task allocation in social animal groups. Behav. Ecol. 32, 1-17. doi: 10.1093/ beheco/araa083

Lörinczi, G., Módra, G., Juhász, O., and Maák, I. (2018). Which tools to use? Choice optimization in the tool-using ant, Aphaenogaster subterranea. Behav. Ecol. 29, 1444-1452. doi: 10.1093/beheco/ary110

Maák, I., Roelandt, G., and d'Ettorre, P. (2020). A small number of workers with specific personality traits perform tool use in ants. Elife 9:e61298. doi: 10.7554/ eLife. 61298

Mailleux, A. C., Buffin, A., Detrain, C., and Deneubourg, J. L. (2011). Recruitment in starved nests: the role of direct and indirect interactions between scouts and nestmates in the ant Lasius niger. Insect. Soc. 58:559. doi: 10.1007/s00040-0110177-7

Marting, P. R., Wcislo, W. T., and Pratt, S. C. (2018). Colony personality and plant health in the Azteca-Cecropia mutualism. Behav. Ecol. 29, 264-271. doi: 10.1093/beheco/arx165

Mather, J. A., and Anderson, R. C. (1993). Personalities of octopuses (Octopus rubescens). J. Compar. Psychol. 107, 336-340. doi: 10.1037/0735-7036.107. 3.336

Mercier, J. L., and Lenoir, A. (1999). A new case of jumping behaviour in ants, as part of the foraging strategy. Compt. Rendus. Acad. Sci. III Sci. Vie. 322, 661-663. doi: 10.1016/S0764-4469(99)80105-X

Modlmeier, A. P., Keiser, C. N., Shearer, T. A., and Pruitt, J. N. (2014). Speciesspecific influence of group composition on collective behaviors in ants. Behav. Ecol. Sociobiol. 68, 1929-1937. doi: 10.1007/s00265-014-1799-3 
Modlmeier, A. P., Liebmann, J. E., and Foitzik, S. (2012). Diverse societies are more productive: a lesson from ants. Proc. Roy. Soc. Lond. B Biol. Sci. 279, 2142-2150. doi: $10.1098 /$ rspb.2011.2376

Möglich, M., Maschwitz, U., and Hölldobler, B. (1974). Tandem calling: a new kind of signal in ant communication. Science 186, 1046-1047. doi: 10.1126/science. 186.4168.1046

Monceau, K., Moreau, J., Richet, J., Motreuil, S., Moret, Y., and DechaumeMoncharmont, F. X. (2017). Larval personality does not predict adult personality in a holometabolous insect. Biol. J. Linn. Soc. 120, 869-878. doi: 10.1093/biolinnean/blw015

Nácarová, J., Veselý, P., and Fuchs, R. (2018). Effect of the exploratory behaviour on a bird's ability to categorize a predator. Behav. Proc. 151, 89-95. doi: 10.1016/ j.beproc.2018.03.021

Nicholson, D. J., Judd, S. P., Cartwright, B. A., and Collett, T. S. (1999). Learning walks and landmark guidance in wood ants (Formica rufa). J. Exp. Biol. 202, 1831-1838.

Niemelä, P. T., Lattenkamp, E. Z., and Dingemanse, N. J. (2015). Personalityrelated survival and sampling bias in wild cricket nymphs. Behav. Ecol. 26, 936-946. doi: 10.1093/beheco/arv036

Novgorodova, T. A. (2015). Organization of honeydew collection by foragers of different species of ants (Hymenoptera: Formicidae): Effect of colony size and species specificity. Eur. J. Entomol. 112, 688-697. doi: 10.14411/eje.2015.077

Oberhauser, F. B., Schlemm, A., Wendt, S., and Czaczkes, T. J. (2019). Private information conflict: Lasius niger ants prefer olfactory cues to route memory. Anim. Cogn. 22, 355-364. doi: 10.1007/s10071-019-01248-3

Otto, D. (1958). Über die Arbeitsteilung im Staate von Formica Rufa Rufo-Pratensis Minor Gössw. und Ihre Verhaltensphysiologischen Grundlagen. Berlin: Dtsch Akad Landwirtschaftswiss.

Pamminger, T., Foitzik, S., Kaufmann, K. C., Schützler, N., and Menzel, F. (2014). Worker personality and its association with spatially structured division of labor. PLoS One 9:e79616. doi: 10.1371/journal.pone.0079616

Parmentier, T., Dekoninck, W., and Wenseleers, T. (2015). Context-dependent specialization in colony defence in the red wood ant Formica rufa. Anim. Behav. 103, 161-167. doi: 10.1016/j.anbehav.2015.02.023

Pasquier, G., and Grüter, C. (2016). Individual learning performance and exploratory activity are linked to colony foraging success in a mass-recruiting ant. Behav. Ecol. 16, 1702-1709. doi: 10.1093/beheco/arw079

Pfeffer, S., Wahl, V., and Wolf, H. (2020). Accuracy and spread of nest search behaviour in the Saharan silver ant, Cataglyphis bombycina, and in the salt pan species, Cataglyphis fortis. Anim. Cogn. 23, 1107-1117. doi: 10.1007/s10071020-01371-6

Pinter-Wollman, N. (2012). Personality in social insects: how does worker personality determine colony personality? Cur. Zool. 58, 580-588. doi: 10.1093/ czoolo/58.4.580

Piqueret, B., Sandoz, J. C., and d'Ettorre, P. (2019). Ants learn fast and do not forget: associative olfactory learning, memory and extinction in Formica fusca. R. Soc. Open Sci. 6:190778. doi: 10.1098/rsos.190778

Planqué, R., Van Den Berg, B., and Franks, N. R. (2010). Recruitment strategies and colony size in ants. PLoS One. 5:e11664. doi: 10.1371/journal.pone.0011664

Powell, S., Price, S. L., and Kronauer, D. J. (2020). Trait evolution is reversible, repeatable, and decoupled in the soldier caste of turtle ants. Proc. Natl. Acad. Sci. U.S.A. 117, 6608-6615. doi: 10.1073/pnas.1913750117

Price, R. A., Grüter, C., Hughes, W. H., and Evison, S. E. F. (2016). Symmetry breaking in mass-recruiting ants: extent of foraging biases depends on resource quality. Behav. Ecol. Sociobiol. 70, 1813-1820. doi: 10.1007/s00265-016-2187-y

Purcell, J., Brelsford, A., Wurm, Y., Perrin, N., and Chapuisat, M. (2014). Convergent genetic architecture underlies social organization in ants. Cur. Biol. 24, 2728-2732. doi: 10.1016/j.cub.2014.09.071

Putyatina, T. S. (2007). The choice of foraging strategy as a mechanism for the coexistence of Myrmica species (Hymenoptera, Formicidae) in a multispecific ant association. Entmol. Rev. 87, 650-657. doi: 10.1134/S0013873807060024

Qiu, B., Larsen, R. S., Chang, N. C., Wang, J., Boomsma, J. J., and Zhang, G. (2018). Towards reconstructing the ancestral brain gene-network regulating caste differentiation in ants. Nat. Ecol. Evol. 2, 1782-1791. doi: 10.1038/s41559018-0689-x

Ratnieks, F. L., and Shackleton, K. (2015). Does the waggle dance help honey bees to forage at greater distances than expected for their body size? Front. Ecol. Evol. 3:31. doi: $10.3389 /$ fevo.2015.00031
Razin, N., Eckmann, J. P., and Feinerman, O. (2013). Desert ants achieve reliable recruitment across noisy interactions. J. R. Soc. Interface. 10:20130079. doi: 10.1098/rsif.2013.0079

Réale, D., Garant, D., Humphries, M. M., Bergeron, P., Careau, V., and Montiglio, P. O. (2010). Personality and the emergence of the pace-of-life syndrome concept at the population level. Proc. Roy. Soc. Lond. B Biol. Sci. 365, 4051-4063. doi: $10.1098 /$ rstb.2010.0208

Reeves, D. D., and Moreau, C. S. (2019). The evolution of foraging behavior in ants (Hymenoptera: Formicidae). Arthropod Syst. Phylo. 77, 351-363. doi: 10.26049/ASP77-2-2019-1

Retana, J., and Cerdá, X. (1991). Behavioural variability and development of Cataglyphis cursor ant workers (Hymenoptera, Formicidae). Ethology. 89, 275286. doi: 10.1111/j.1439-0310.1991.tb00373.x

Reznikova, J. I. (Z.) (1982). Interspecific communication among ants. Behaviour 80, 84-95. doi: 10.1163/156853982X00454

Reznikova, Z. (1983). Interspecies relations in ants (in Russian). Novosibirsk: Nauka.

Reznikova, Z. (2007). Animal Intelligence: From Individual to Social Cognition. Cambridge, MA: Cambridge University Press. doi: 10.1016/j.intell.2009.04.004

Reznikova, Z. (2008). Experimental paradigms for studying cognition and communication in ants (Hymenoptera: Formicidae). Myrm. News. 11, 201214.

Reznikova, Z. (2011). Division of labour and communication at the individual level in highly social Formica ants (Hymenoptera: Formicidae). Russian Entomol. J. 20, 315-319.

Reznikova, Z. (2017). Studying Animal Language Without Translation: An Insight From Ants. Cham: Springer International Publishing. doi: 10.1007/978-3-31944918-0

Reznikova, Z. (2018). “Ants. individual and social cognition,” in Field and Laboratory Methods in Animal Cognition: A Comparative Guide, eds N. BuenoGuerra and F. Amici (Cambridge, MA: Cambridge University Press), 8-30. doi: $10.1017 / 9781108333191.003$

Reznikova, Z. (2020). Spatial cognition in the context of foraging styles and information transfer in ants. Anim. Cogn. 23, 1143-1159. doi: 10.1007/s10071020-01423-x

Reznikova, Z. I., and Novgorodova, T. A. (1998). The importance of individual and social experience for interaction between ants and symbiotic aphids. Dokl. Biol. Sci. 359, 173-175.

Reznikova, Z., and Dorosheva, E. (2013). Catalog learning: Carabid beetles learn to manipulate with innate coherent behavioral patterns. Evol. Psychol. 11:147470491301100304. doi: 10.1177/147470491301100304

Reznikova, Z., and Dorosheva, H. (2004). Impacts of red wood ants Formica polyctena on the spatial distribution and behavioural patterns of ground beetles (Carabidae). Pedobiologia 48, 15-21. doi: 10.1016/j.pedobi.2003.06.002

Reznikova, Z., and Ryabko, B. (1994). Experimental study of the ants communication system with the application of the Information Theory approach. Mem. Zool. 48, 219-236.

Reznikova, Z., and Ryabko, B. (2011). Numerical competence in animals, with an insight from ants. Behaviour 148, 405-434. doi: 10.1163/000579511X568562

Reznikova, Z., Panteleeva, S., and Vorobyeva, N. (2019). Precise relative-quantity judgement in the striped field mouse Apodemus agrarius Pallas. Anim. Cogn. 22, 277-289. doi: 10.1007/s10071-019-01244-7

Ricklefs, R. E., and Wikelski, M. (2002). The physiology/life-history nexus. Trends Ecol. Evol. 17, 462-468. doi: 10.1016/S0169-5347(02)02578-8

Robinson, E. J., Jackson, D. E., Holcombe, M., and Ratnieks, F. L. (2005). “No entry” signal in ant foraging. Nature 438, 442-442. doi: 10.1038/438442a

Robson, S. K., and Traniello, J. F. (2002). Transient division of labor and behavioral specialization in the ant Formica schaufussi. Naturwissenschaften 89, 128-131. doi: 10.1007/s00114-002-0300-8

Romiguier, J., Rolland, J., Morandin, C., and Keller, L. (2018). Phylogenomics of palearctic Formica species suggests a single origin of temporary parasitism and gives insights to the evolutionary pathway toward slave-making behaviour. BMC Evol. Biol. 18:40. doi: 10.1186/s12862-018-1159-4

Rosengren, R. (1977). Foraging strategy of wood ants (Formica rufa group) I. Age polyethism and topographic traditions. Acta. Zool. Fenn. 149, 2-30.

Rosengren, R., and Fortelius, W. (1987). Trail communication and directional recruitment to food in red wood ants (Formica). Ann. Zool. Fenn. 24, $137-146$. 
Rosengren, R., and Sundström, L. (1987). The foraging system of a red wood ant colony (Formica s. str.) - collecting and defending food through an extended phenotype. Exp. Suppl. 54, 117-137.

Salo, O., and Rosengren, R. (2001). Memory of location and site recognition in the ant Formica uralensis (Hymenoptera: Formicidae). Ethology. 107, 737-752. doi: 10.1046/j.1439-0310.2001.00702.x

Sasaki, T., Danczak, L., Thompson, B., Morshed, T., and Pratt, S. C. (2020). Route learning during tandem running in the rock ant Temnothorax albipennis. J. Exp. Biol. 223:jeb221408. doi: 10.1242/jeb.221408

Scheffers, B. R., Joppa, L. N., Pimm, S. L., and Laurance, W. F. (2012). What we know and don't know about Earth's missing biodiversity. Trends Ecol. Evol. 27, 501-510. doi: 10.1016/j.tree.2012.05.008

Schmid-Hempel, P. (1984). Individually different foraging methods in the desert ant Cataglyphis bicolor (Hymenoptera, Formicidae). Behav. Ecol. Sociobiol. 14, 263-271. doi: 10.1007/BF00299497

Schultheiss, P., and Nooten, S. S. (2013). Foraging patterns and strategies in an Australian desert ant. Austral Ecol. 38, 942-951. doi: 10.1111/aec.12037

Schultheiss, P., Raderschall, C. A., and Narendra, A. (2015). Follower ants in a tandem pair are not always naïve. Sci. Rep. 5:10747. doi: 10.1038/srep10747

Seeley, T. D. (2009). The Wisdom of the Hive: The Social Physiology of Honey Bee Colonies. Cambridge, MA: Harvard University Press.

Segev, U., Burkert, L., Feldmeyer, B., and Foitzik, S. (2017). Pace-of-life in a social insect: behavioral syndromes in ants shift along a climatic gradient. Behav. Ecol. 28, 1149-1159. doi: 10.1093/beheco/arx079

Sheehan, M. J., and Tibbetts, E. A. (2011). Specialized face learning is associated with individual recognition in paper wasps. Science 334, 1272-1275. doi: 10 . $1126 /$ science. 1211334

Sih, A., and Del Giudice, M. (2012). Linking behavioural syndromes and cognition: a behavioural ecology perspective. Proc. Roy. Soc. Lond. B Biol. Sci. 367, 2762-2772. doi: 10.1098/rstb.2012.0216

Sih, A., and Watters, J. V. (2005). The mix matters: behavioural types and group dynamics in water striders. Behaviour 142, 1417-1431. doi: 10.1163/ 156853905774539454

Sih, A., Bell, A. M., Johnson, J. C., and Ziemba, R. E. (2004a). Behavioral syndromes: an integrative overview. Q. Rev. Biol. 79, 241-277. doi: 10.1086/ 422893

Sih, A., Bell, A., and Johnson, J. C. (2004b). Behavioral syndromes: an ecological and evolutionary overview. Trends Ecol. Evol. 19, 372-378. doi: 10.1016/j.tree. 2004.04.009

Simola, D. F., Graham, R. J., Brady, C. M., Enzmann, B. L., Desplan, C., Ray, A., et al. (2016). Epigenetic (re) programming of caste-specific behavior in the ant Camponotus floridanus. Science 351:aac6633. doi: 10.1126/science.aac6633

Sommer, S., Weibel, D., Blaser, N., Furrer, A., Wenzler, N. E., Rössler, W., et al. (2013). Group recruitment in a thermophilic desert ant, Ocymyrmex robustior. J. Compar. Physiol. A 199, 711-722. doi: 10.1007/s00359-013-0830-x

Stüger, R. (1931). Uber das mitteilungsvermgen der waldameise beim auffinden und transport eines beutesttickes. Z. Wiss. Ins. 26, 125-137.

Sudd, J. H. (1960). The foraging method of Pharaoh's ant, Monomorium pharaonis (L.). Anim. Behav. 8, 67-75. doi: 10.1016/0003-3472(60)90011-7

Suzzoni, J. P., Ghaemi, F., and Depambour, I. (1991). Modalités de l'orientation spatiale chez Camponotus aethiops: utilisation de repères olfactifs et visuels au sol. Actes Coll. Insect. Soc. 6, 179-186.

Tanner, C. J. (2009). Individual experience-based foraging can generate community territorial structure for competing ant species. Behav. Ecol. Sociobiol. 63, 591603. doi: 10.1007/s00265-008-0694-1

Tibbetts, E. A. (2002). Visual signals of individual identity in the wasp Polistes fuscatus. Proc. Roy. Soc. Lond. B Biol. Sci. 269, 1423-1428. doi: 10.1098/rspb. 2002.2031

Traniello, F. A. (1977). Recruitment behavior, orientation, and the organization of foraging in the carpenter ant Camponotus pennsylvanicus DeGeer. Behav. Ecol. Sociobiol. 2, 61-79. doi: 10.1007/BF00299289

Traniello, J. F. (1989). Foraging strategies of ants. Ann. Rev. Entomol. 34, 191-210.

Trible, W., and Kronauer, D. J. (2017). Caste development and evolution in ants: it's all about size. J. Exp. Biol. 220, 53-62. doi: 10.1242/jeb.145292
Udino, E., Perez, M., Carere, C., and d'Ettorre, P. (2017). Active explorers show low learning performance in a social insect. Cur. Zool. 63, 555-560. doi: 10.1093/cz/ zow101

Vaes, O., Perna, A., and Detrain, C. (2020). The effect of nest topology on spatial organization and recruitment in the red ant Myrmica rubra. Sci. Nat. 107, 1-14. doi: 10.1007/s00114-020-01675-0

Verhaeghe, J. C. (1982). Food recruitment in Tetramorium impurum (Hymenoptera: Formicidae). Insect. Soc. 29, 67-85. doi: 10.1007/BF02224528

von Frisch, K. (1967). The Dance Language and Orientation of Bees. Cambridge, MA: Harvard University Press.

Wang, J., Wurm, Y., Nipitwattanaphon, M., Riba-Grognuz, O., Huang, Y.-C., Shoemaker, D., et al. (2013). A Y-like social chromosome causes alternative colony organization in fire ants. Nature 493, 664-668. doi: 10.1038/nature 11832

Webster, M. M., and Ward, A. J. (2011). Personality and social context. Biol. Rev. 86, 759-773. doi: 10.1111/j.1469-185X.2010.00169.x

Wehner, R., and Rössler, W. (2013). "Bounded plasticity in the desert ant's navigational tool kit," in Handbook of Behavioral Neuroscience, eds R. Menzel and P. R. Benjamin (Amsterdam: Elsevier), 514-529. doi: 10.1016/B978-0-12415823-8.00039-3

Wheeler, W. M. (1911). The ant-colony as an organism. J. Morphol. 22, 307-325.

Wheeler, W. M. (1920). The temitodoxa, or biology and society. Sci. Mon. 10, 113-124.

Wheeler, W. M. (1928). The Social Insects. London: Kegan Paul, Trench, Trübner \& Co.Ltd.

Wills, B. D., Powell, S., Rivera, M. D., and Suarez, A. V. (2018). Correlates and consequences of worker polymorphism in ants. Ann. Rev. Entomol. 63, 575-598. doi: 10.1146/annurev-ento-020117-043357

Wilson, A. D., Whattam, E. M., Bennett, R., Visanuvimol, L., Lauzon, C., and Bertram, S. M. (2010). Behavioral correlations across activity, mating, exploration, aggression, and antipredator contexts in the European house cricket, Acheta domesticus. Behav. Ecol. Sociobiol. 64, 703-715. doi: 10.1007/ s00265-009-0888-1

Wilson, D. S., and Sober, E. (1989). Reviving the superorganism. J. Theor. Biol. 136, 337-356. doi: 10.1016/S0022-5193(89)80169-9

Wilson, E. O. (1962). Chemical communication among workers of the fire ant Solenopsis saevissima (Fr. Smith) 1. The organization of mass-foraging. Anim. Behav. 10, 134-147. doi: 10.1016/0003-3472(62)90141-0

Wilson, E. O. (1971). The Insect Societies. Cambridge, MA: Belknap.

Wilson, E. O., and Hölldobler, B. (2005). Eusociality: origin and consequences. Proc. Natl. Acad. Sci. U.S.A. 102, 13367-13371. doi: 10.1073/pnas.050585 8102

Wilson, V., Guenther, A., Øverli, Ø, Seltmann, M. W., and Altschul, D. (2019). Future directions for personality research: contributing new insights to the understanding of animal behavior. Animals 9:240. doi: 10.3390/ani9050240

Wolf, M., Van Doorn, G. S., Leimar, O., and Weissing, F. J. (2007). Life-history trade-offs favour the evolution of animal personalities. Nature 447, 581-584. doi: $10.1038 /$ nature 05835

Wray, M. K., Mattila, H. R., and Seeley, T. D. (2011). Collective personalities in honeybee colonies are linked to colony fitness. Anim. Behav. 81, 559-568. doi: 10.1016/j.anbehav.2010.11.027

Wright, C. M., Lichtenstein, J. L., Doering, G. N., Pretorius, J., Meunier, J., and Pruitt, J. N. (2019). Collective personalities: present knowledge and new frontiers. Behav. Ecol. Sociobiol. 73:31. doi: 10.1007/s00265-019-2639-2

Conflict of Interest: The author declares that the research was conducted in the absence of any commercial or financial relationships that could be construed as a potential conflict of interest.

Copyright (c) 2021 Reznikova. This is an open-access article distributed under the terms of the Creative Commons Attribution License (CC BY). The use, distribution or reproduction in other forums is permitted, provided the original author(s) and the copyright owner(s) are credited and that the original publication in this journal is cited, in accordance with accepted academic practice. No use, distribution or reproduction is permitted which does not comply with these terms. 